\title{
PSYCHOMETRIC TESTS OF THE ACTION OF ALCOHOL.
}

\author{
A VISIT TO THE LABORATORY OF PROFESSOR \\ KRAEPELIN.
}

By THEODORE NEILD, B.A., J.P.,

Formerly Principal of the Dalton Hall, Owens, Manchester.

THE research work in experimental psychology that has been done at Heidelberg during nearly two decades now has greatly influenced the views of men of science as to the action upon the brain of alcohol in moderate doses. Professor Kraepelin, an alienist of high repute, began these investigations without bias; alcohol was only one of several drugs whose effect upon the brain he wished to measure. The results he obtained with regard to it were long known only to the few who were at once students of psychiatry and also German scholars. But as, in the course of years, one important "Arbeit" after another issued from the Heidelberg laboratory, each widening the field of research, and each corroborating its forerunners, the attention of a larger circle was attracted, and the results of Kraepelin's researches at length made their way into medical text-books. To those engaged in the "study and cure of inebriety" the conclusions of the professor and of his co-workers Aschaffenburg, Fürer, Smith, Ach, Kürz, Mayer, Rüdin, and others, were especially welcome, as confirming in many ways their own rough observations, and as doing this with a scientific accuracy and thoroughness which went far towards placing beyond cavil the results obtained.

Dr. Pierce, the able head of The Retreat at York, first drew the writer's attention some years ago to the Heidelberg researches; and it was due to him again, and in his company, that a six days' visit was paid last month to the place where Kraepelin and that great student of the cortex, Nissl, have done their work. We were not among the number of those who are "sceptical of attempts to measure the mind or to examine consciousness with laboratory 
instruments," but we had certainly felt that much depends upon the acumen, sagacity, and freedom from bias (conscious or unconscious) of the deviser, conductor, and interpreter of mental tests. This made us wishful to see the man who has either carried out, or else directed, so many important researches into the action of alcohol. We also felt that it would be easier to evaluate, and in some cases to understand, some of the results after we had studied the instruments and methods by which they were obtained.

Some account of these instruments may interest the readers of the British Journal of Inebriety, though, of course, those at all acquainted with psychometry will be familiar with some of them. As simple as any is the apparatus by which to gauge the speed with which a sound is recognised and responded to. Upon a table is a chronoscope, showing thousandths of a' second, and communicating electrically with two spring buttons at some distance apart. The operator and the subject, both doctors and both trained in this kind of work, are each in charge of one of these buttons. First, the reading of the chronoscope is noted. Then, after the room has been darkened, the operator smartly depresses his button, which starts the chronoscope. The subject hears the click and at once depresses his own button, which throws the chronoscope fingers out of gear. The reading is again noted, and this, subtracted from the first reading, gives the whole time taken-the "reaction time."

Nothing can here be said of the accessory apparatus by which the truth of the chronograph has to be frequently tested. Somewhat similar instruments are employed to test the reaction time of the eye by means of flashes of light. But a more elaborate apparatus is needed to measure the capacity of the eye quickly to seize, and accurately to reproduce what has been so seized. This is termed the "shooting-slide." The light employed in using this instrument is artificial, in order not to vary, and shines through a semi-transparent screen. In front of this screen the subject sits in a darkened room. Between him and the illuminated screen is an opaque screen, placed in the line of his focus, and having in its centre a square opening through which comes the light. Across this opening the operator shoots at various speeds, by the release of springs of 'different strength, a series of glass slides. Each slide has nine capital letters upon it, well spaced and variously arranged. The subject has to read as many 
of these letters as he can whilst the slide glances by. It is curious how distinctly all the three rows of letters are visualised in this tiny fraction of a second, but equally curious how hard it is, for the unpractised observer at least, to reproduce to the operator all that has been seen. To test speed and accuracy of reading words or syllables, these are arranged spirally upon a cylinder which revolves so as to bring each word in turn before the subject for a fraction of a second. In experiments where the operator has to speak and the subject to reply, the time occupied is ascertained by apparatus arranged so that the opening of the operator's lips sets the chronoscope going, and the opening of the subject's lips throws the fingers out of gear.

The instrument by which the time taken by the subject in making association-replies is measured is simple but excellent. Words of all kinds, representing all sorts of objects, ideas, sounds, etc., are printed in bold type upon cards. These cards are successively presented to the subject, who has to name some noun which the presented word calls up, and which is associated with it in some previously agreed manner. The finger-stroke which flashes up the card in front of the subject sets the chronoscope in motion; when he speaks his reply into a telephonic mouthpiece he throws the fingers out of gear. This gives the time occupied; a far more delicate task is afterwards to sort the answers, given under the various conditions, so as to gauge their respective intellectual value.

The investigation of variations in handwriting under small doses of alcohol was that about which the writer was most inclined to be sceptical. It was, however, the apparatus for testing these variations which Professor Kraepelin seemed, perhaps, to describe with most satisfaction; and it is most certainly ingenious and delicate. Tracings upon smoked paper record the exact pressure of the pen at every part of the line written, together with the precise time taken over the various letters-again to the thousandth of a second, but in this case by the well-known tuning-fork arrangement. Then a special micrometer employed afterwards on the writing completes the analysis. The writer was much impressed by what he saw, and will now turn with much greater confidence to the monograph of Dr. M. Mayer.*

* "Ueber die Beeinflussung der Schrift durch den Alcohol," von Martin Mayer; "Psychologische Arbeiten," herausgegeben von Emil Kraepelin, Band III., Heft 4. Leipzig: W. Engelmann. 
Tests of handwriting, it is true, border more distinctly than any of the foregoing upon the domain of muscle. Measurements of muscle pure and simple, if we may so speak, are made, of course, with the ergograph. This instrument is often employed at Heidelberg in experiments with alcohol, as all readers of the "Psychologische Arbeiten" know. It was interesting to see the originals of well-known diagrams of ergographic work, but the instrument itself was engaged upon researches outside the scope of this paper.

It will be easily understood that the labour of research with any of the above instruments is enormous. A large number of experiments is made each day and the average taken. These are repeated, at the same hour and under the same conditions, for many consecutive days, in periods alternately without and with alcohol (or whatever other drug is in question). The quickening effect of practice, and the slowing effect of fatigue, have, inter alia, to be ascertained and allowed for. The alcohol is given in various doses, either swallowed at once, or sipped, or repeated at certain intervais; and the experiments are made either immediately afterwards, or when a varying number of hours have elapsed, and all this has to be gone through with more than one subject to avoid idiosyncrasies. Much, however, as has already been done, Professor Kraepelin still feels " the need for extending the experiments, and for varying the conditions in various directions."*

The professor remarked to us that, whilst anyone could perform the experiments, it takes six months to train a man (doctor) to act as operator. As said above, we had felt that far more than training is needful for research in mental processes. But, after watching Professor Kraepelin in the various departments of his work, we were entirely agreed that he has remarkable qualifications for the task in question. To the writer he seemed to unite the best qualities of a German, a French, and an English man of science. His results have remained practically unchallenged, and have been accepted by many of the highest authorities. Sir Victor Horsley's Lees-Raper lecture unfortunately was not published, but from the report it would seem that he based some part of his

- "Ueber die Beeinflussung psychischer Vorgänge durch regelmässigen Alkoholgenuss," von E. Kürz and E. Kraepelin (op. cit., Band III., Heft 3. p. 457). 
argument upon the findings of Kraepelin, as well as upon those of Nissl, some of whose investigations into the diseases of the cortex gave us a rare treat during our visit. It is true, as Professor Kraepelin reminded us, that the experiments made by himself have not yet been repeated, but all that has so far appeared has been confirmatory.*

Kraepelin states, it will be remembered, that the maximum dose of alcohol after which no depression of mental function is subsequently to be detected is about 7.5 grammes. We asked him if any work had been done to test whether there is any cumulative effect resulting from the daily repetition of a dose apparently nonparalysant. He said it had not, pointing out the great length of any such experiment, which would have to be conducted in periods of six months alternately with and without alcohol. But he added that he had himself practically no doubt that some cumulative effect is produced. We questioned him also as to that brief quickening of the more automatic mental processes which precedes their period of depression after small doses of alcohol. This quickening has been set down to the increase of blood in the brain caused by the paralysis of the constrictive nerves of the arteries. To the writer it has never been easy to see why this increase should not quicken all the mental processes equally. Professor Kraepelin, we found, does not accept the extra-blood explanation, but sets the quickening down to that psychomotorische Erregung of which he and his school speak,--by which they mean, apparently, something akin to those ill-governed but rapid movements which are observed in some forms of insanity and in delirium, and are attributed to the paralysis of the highest (inhibitive) functions of the brain.

We were fortunate in going when we did, for Professor Kraepelin has been "called" to Munich, and it was his last fortnight at the University of Heidelberg. Let us hope that from his new home he may long send us out fresh researches upon the action of alcohol, and also that some Society may be found willing to translate not these alone but also those he has already given us.

*Dr. Helenius, in " Die Alkoholfrage," p. 89, quotes a promise given by Professor Sims Woodhead in Igoo to repeat some of these experiments. We shall await his Lees-Raper lecture with the greater eagerness. 